\title{
Management of Traumatic Cervical Spondyloptosis
}

\author{
Hitesh Inder Singh Rai ${ }^{1} \quad$ Kanwaljeet Garg ${ }^{1}$ Deepak Agrawal ${ }^{1, \odot}$ \\ ${ }^{1}$ Department of Neurosurgery \& Gamma-Knife, All India Institute of \\ Address for correspondence Kanwaljeet Garg, MCh, Department \\ Medical Sciences, New Delhi, India \\ of Neurosurgery \& Gamma-Knife, All India Institute of Medical \\ Sciences, New Delhi 110029, India \\ (e-mail: kanwaljeet84@gmail.com).
}

Indian J Neurotrauma:2021;18:14-18
Abstract
Keywords
- ASIA impairment scale
- cervical
- instrumented fusion
- pre-reduction MRI
- spondyloptosis
- traction
- traumatic

Traumatic cervical spondyloptosis is a 3-column fracture-dislocation resulting in a highly unstable spine requiring urgent reduction, stabilization, and fixation. Since its occurrence is not that common, there are a lot of controversies concerning its management. A holistic approach has been proposed regarding the management of traumatic cervical spondyloptosis.

\section{Introduction}

Traumatic cervical spondyloptosis is a 3-column injury that is highly unstable and requires immediate reduction and stabilization, either open or closed. It was first defined in the literature as a complete intercorporal displacement in the cervical spine. ${ }^{1}$ It is a complete segmental disruption leading to devastating consequences. There is no definite consensus when it comes to its management. However, there are several different management options described in the literature ranging from a simple anterior or posterior approach to 540-degree fusions.

\section{Mechanism of Injury}

In this kind of injury, the affected vertebral body is completely dislocated either anterior or posterior to the subjacent vertebral body. Most of these injuries are high-impact trauma cases comprising high-speed road traffic accidents, fall from height, or diving accidents. ${ }^{2}$ Allen et al proposed a mechanistic classification of cervical spine injuries based on direction of forces acting during trauma. ${ }^{2}$ This included six categories: compressive flexion, vertical compression, distractive flexion, compressive extension, distractive extension, and lateral flexion. Each category has various stages graded from least severity to the most.

Based on this classification, spondyloptosis can occur either during stage 4 of distraction flexion (DF4) or stage 5 of compressive extension (CE5). During DF4 injury, the facet joints are completely unhinged/dislocated anteriorly leading to a grossly unstable motion segment causing a "floating vertebra." This also leads to canal compromise and neurological deficits (-Fig. 1). During CE5 injury, there is complete disruption of soft tissues anteriorly as well as posteriorly and the compression force vector causes bilateral posterior arch fractures (lamina/pedicle/facets/combined injuries) leading to anterior vertebral body displacement (-Fig. 2).

\section{Neurological Deficits}

Based on the review of literature, a total of 47 patients with traumatic cervical spondyloptosis have been reported, out of which 9 (19\%) patients have had complete cord injury (ASIA A). Neurological status depends on canal compromise. In DF4 injury, the spinal canal gets compromised as the posterior
DOI https://doi.org/ 10.1055/s-0040-1722554 ISSN 0973-0508. (c) 2021. Neurotrauma Society of India.

This is an open access article published by Thieme under the terms of the Creative Commons Attribution-NonDerivative-NonCommercial-License, permitting copying and reproduction so long as the original work is given appropriate credit. Contents may not be used for commercial purposes, or adapted, remixed, transformed or built upon. (https://creativecommons.org/licenses/by-nc-nd/4.0/).

Thieme Medical and Scientific Publishers Pvt. Ltd. A-12, 2nd Floor, Sector 2, Noida-201301 UP, India 

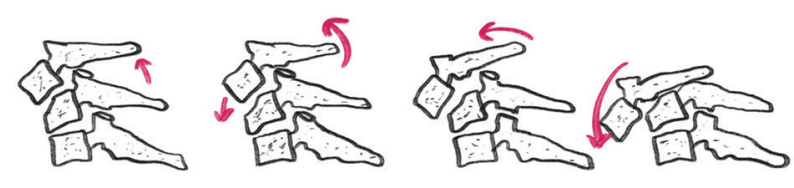

Fig. 1 Flexion-distraction injury showing the various forces acting on the cervical spine with resultant dislocation and jumped facets.

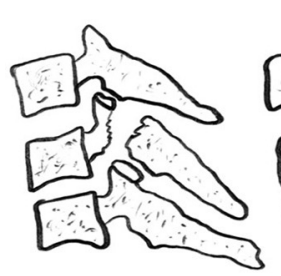

I

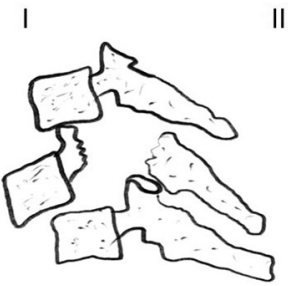

IV

II
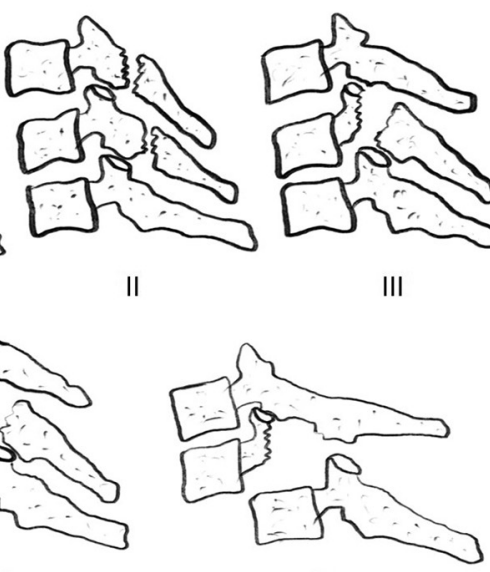

V
Fig. 2 Compressive extension injury is divided into five stages: Stage I: Posterior arch fracture that may be facet, pedicle, or lamina fracture, with or without rotation that can result in mild anterior translation (lateral mass fractures). Stage II: Bilateral lamina fractures (single/multiple levels). Stage III: Bilateral lamina, facet, pedicle fractures without vertebral body displacement (floating lateral mass fractures). Stage IV: As for stage III, with partial anterior vertebral body displacement. Stage V: As for stage III, with $100 \%$ anterior vertebral body displacement.

elements dislocate with the vertebral body as a single segment compressing the cord, leading to neurological deficits. Also, the spinal cord gets kinked during flexion injury leading to worsening of deficits. However, in CE5 injury, the spinal cord may get spared due to the fact that the posterior elements get fractured that leads to the natural decompression and widening of spinal canal. Moreover, due to extension in CE5, the spinal canal maintains the normal lordotic alignment with no resultant kink. Such cases with no neurological deficits have been reported by various authors. ${ }^{3-10}$

\section{Investigations}

After resuscitation and stabilization of vitals, the patient (hard cervical collar on since the time of injury) is screened with cervical spine X-ray with anteroposterior and lateral views. Noncontrast computed tomography (CT) whole spine is done to look for bony anatomy and fracture-dislocations. Magnetic resonance imaging (MRI) cervical spine is a valuable tool to assess for any anterior cord compression (disc prolapse, hematoma, or fracture fragment). Some authors propose to get MRI done before applying traction as traction can worsen the anterior compression and can result in neurological deterioration., ${ }^{411,12} \mathrm{CT}$ angiography or MR angiography is done to rule out vertebral artery injury. Radiology of a case who sustained cervical spine injury has been shown in - Fig. 3 .

\section{Presurgical Management}

Presurgical management starts at the scene of accident by immobilizing the patient with a hard cervical collar and shifting the patient via log rolling. On arriving at the hospital, ABCDE are assessed and patient is resuscitated. Cervical immobilization (hard cervical collar) is the norm until cervical spinal injury has been ruled out.

The ultimate goal of any intervention in this scenario is to preserve neurology and prevent further neurologic injury. ${ }^{10}$ The best way to achieve it is by applying traction. The traction provides time between injury and surgical stabilization. The traction may restore the anatomic alignment thus converting a grade 5 listhesis to a lower grade or even complete reduction in addition to providing stability. The traction should be applied in a conscious patient who can be assessed clinically. ${ }^{13}$

The traction is applied $2 \mathrm{~cm}$ posterior to the interaural line below the equator of the skull to cause a flexion moment that facilitates reduction in facet dislocation. The pins are tightened until spring loaded indicator protrudes $1 \mathrm{~mm}$ above surface (this is the equivalent of $139 \mathrm{~N}$ [14 kg] of force) (-Fig. 4).

The traction is applied with an initial weight of $4 \mathrm{~kg}$ that is then gradually increased by $4 \mathrm{~kg}$ increments every 20 minutes till complete reduction in dislocation is achieved or the patient shows neurological deterioration (whichever comes earliest). Serial radiographs are done after each weight increment. The maximum weight used is up to $63 \mathrm{~kg} .{ }^{14}$ -Fig. 5 shows post-traction imaging of a partially reduced cervical spondyloptosis.

\section{Management}

A pre-reduction MRI is still a controversial thing when it comes to stabilizing the cervical spine. Some authors suggest to get an MRI before applying traction to rule out anterior compression, ${ }^{11,12}$ whereas there are others who believe that applying traction does not worsen the anterior compression (if any). ${ }^{9,10,13,15,16}$ These authors take into account the spinal canal widening due to fracture of posterior elements, which further makes the traction safer.

Instrumented versus uninstrumented fusion? Bhojraj and Shahane ${ }^{1}$ described a case of spondyloptosis caused by obstetric trauma that caused a delayed neurological deficit. They managed it with corpectomy and autologous bone graft without instrumentation. Similarly, Shah and Rajshekhar ${ }^{17}$ did similar uninstrumented fusion. But this resulted in long-term immobilization of the patient that can be avoided with the use of instrumentation. Instrumented fusion is preferred by most authors due to a more robust construct and early mobilization. 

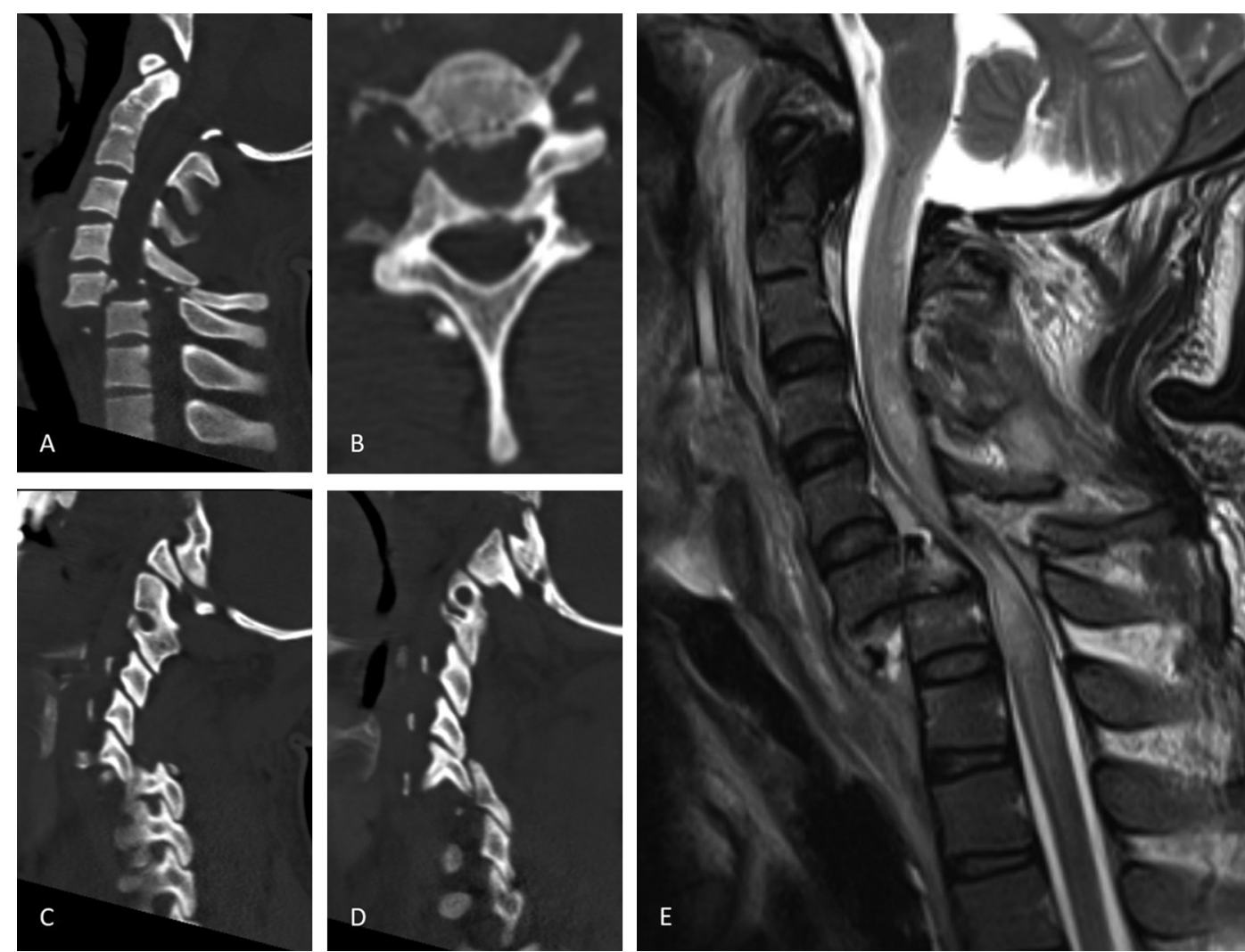

Fig. 3 (A and B) Preoperative noncontrast computed tomography cervical spine showing C6-7 spondyloptosis. (C and D) Both right and left facets have dislocated anteriorly. (E) Preoperative magnetic resonance imaging showing severe canal compromise with cord edema. There is a fragmented disc and hematoma posterior to C6 vertebral body.

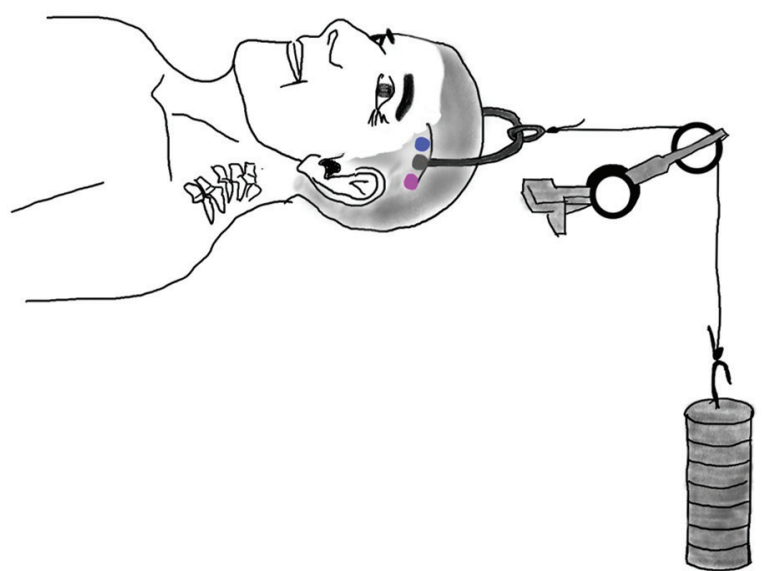

Fig. 4 Cervical traction using Gardner Wells tongs showing three markers just below the superior temporal line: gray on interaural line, blue $2 \mathrm{~cm}$ anterior, and pink $2 \mathrm{~cm}$ posterior to the interaural line. Traction at blue marker will cause extension of neck and flexion at pink marker.

Single versus combined approach? A combined approach is recommended as it is a highly unstable fracture. ${ }^{3,4,16}$ - Fig. 6 shows a 360-degree fusion in a case of cervical spondyloptosis. However, some authors have reported anterior only or posterior only approaches with good results. . $^{1,6,9,12,17,18}$
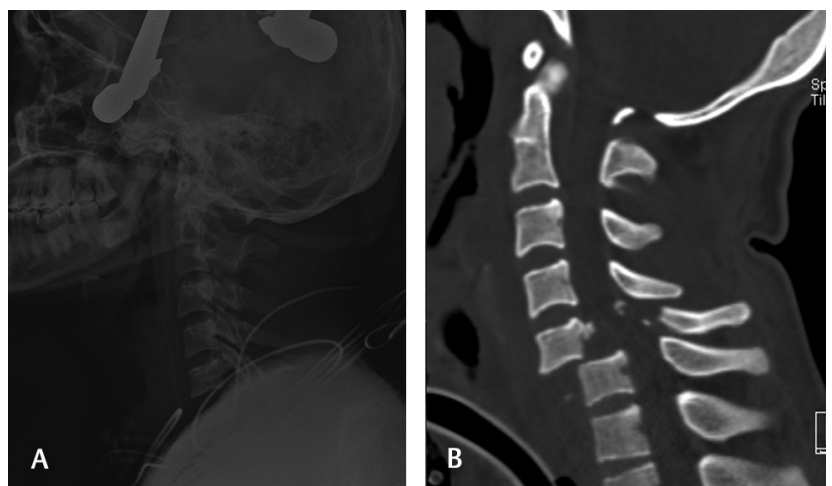

Fig. 5 Post-traction X-ray (A) and CT scan (B) showing incomplete reduction.

Dahdaleh et al, ${ }^{12}$ however, proposed that after initial anterior fusion, posterior fusion is done only if there is documented segmental instability on intraoperative fluoroscopy.

Which approach to do initially? An anterior approach is done initially if there is documented anterior compression on MRI and after reduction and anterior instrumented fusion, a posterior approach (360 degrees) is done. If anterior open reduction fails, a posterior approach is utilized to reduce the joint dislocation and after posterior instrumented fusion, anterior approach follows (540 degrees). ${ }^{19}$ If there is no 

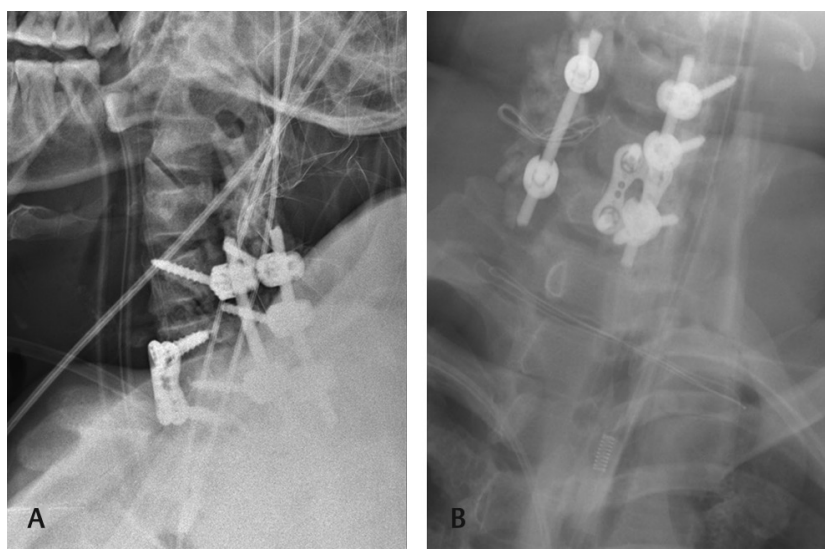

Fig. 6 The patient was approached anteriorly first as there was anterior compression (disc + hematoma). Postoperative X-ray showing C6-7 ACDF + plating with posterior C5-7 instrumented fusion.

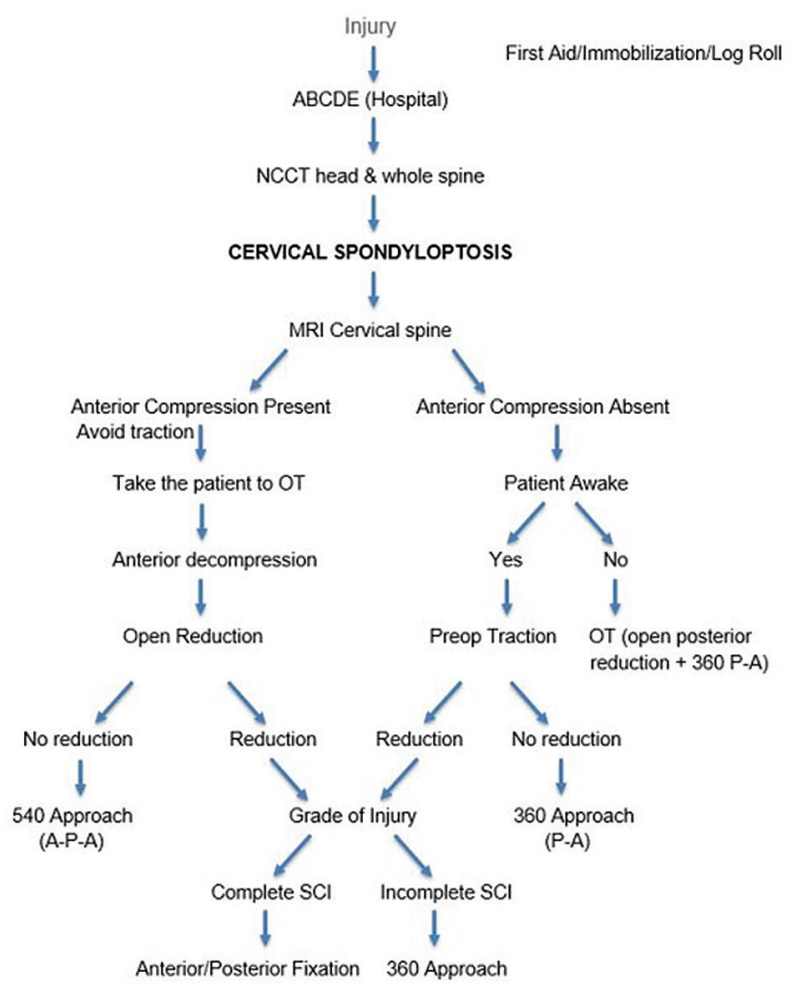

Fig. 7 Management of traumatic cervical spondyloptosis. MRI, magnetic resonance imaging; NCCT, noncontrast computed tomography; OT, operation theater.

anterior compression on MRI, a posterior approach is utilized first followed by an anterior approach (360 degrees). Failure of closed reduction without anterior compression warrants an initial posterior approach followed by anterior approach. ${ }^{3,20}$

Complete versus incomplete injury? In a patient with an incomplete injury, circumferential fusion is preferred under strict neuromonitoring. ${ }^{16,19}$ Patients with complete injuries (ASIA-A) and/or associated comorbidities can be managed via anterior approach only as they may have unstable vitals and a dismal prognosis. ${ }^{19}$

The management algorithm has been summarized in $\boldsymbol{~ - ~ F i g . ~} 7$.

\section{Funding}

None.

\section{Conflict of Interest}

None declared.

\section{References}

1 Bhojraj SY, Shahane SM. Posttraumatic cervical spondyloptosis at C6-7 with late-onset cord compression: a new clinical entity. Case report. J Neurosurg 1992;77(5):792-794

2 Allen BL Jr, Ferguson RL, Lehmann TR, O’Brien RP. A mechanistic classification of closed, indirect fractures and dislocations of the lower cervical spine. Spine 1982;7(1):1-27

3 Ahn T-K, Chung Y-S, Kim M-S, Han I. High-grade traumatic spondylolisthesis of $\mathrm{C} 7$ on $\mathrm{T} 1$ with no neurological deficit. The Nerve 1970;1(1):37-39

4 Menku A, Kurtsoy A, Tucer B, Oktem IS, Akdemir H. The surgical management of traumatic C6 - C7 spondyloptosis in a patient without neurological deficits. Minim Invasive Neurosurg 2004;47(4):242-244

5 Munakomi S, Bhattarai B, Cherian I. Traumatic cervical spondyloptosis in a neurologically stable patient: a therapeutic challenge. Case Rep Crit Care 2015;2015:54091910. Doi: 1155/2015/540919

6 Payne C, Gigliotti MJ, Castellvi A, Yu A, Lee PS. Traumatic C7T1 spondyloptosis without neurological injury: case review and surgical management. Interdiscip Neurosurg 2020 20:100678. Doi: 10.1016/j.inat.2020.100678

7 Srivastava SK, Agrawal KM, Sharma AK, Agrawal MD, Bhosale SK, Renganathan SR. C3-C4 spondyloptosis without neurological deficit-a case report. Spine J 2010;10(7): e16-e20

8 Ramieri A, Domenicucci M, Cellocco P, Lenzi J, Dugoni DE, Costanzo G. Traumatic spondylolisthesis and spondyloptosis of the subaxial cervical spine without neurological deficits: closed re-alignment, surgical options and literature review. Eur Spine J 2014;23(Suppl 6) :658-663

9 Acibas C, Gurkanlar D. Spondyloptosis in a patient without neurological deficit: a case report Bir Hastada Travma Sonras Nörolojik. Turk Neurosurg 2010;20(2):257-260

10 Tumialán LM, Dadashev V, Laborde DV, Gupta SK. Management of traumatic cervical spondyloptosis in a neurologically intact patient: case report. Spine 2009;34(19):E703-E708

11 Darsaut TE, Ashforth R, Bhargava R, et al. A pilot study of magnetic resonance imaging-guided closed reduction of cervical spine fractures. Spine 2006;31(18):2085-2090

12 Dahdaleh NS, Dlouhy BJ, Greenlee JDW, Smoker WRK, Hitchon PW. An algorithm for the management of posttraumatic cervicalspondyloptosis.JClinNeurosci2013;20(7):951-957.Doi: 10.1016/j.jocn.2012.08.008

13 GelbDE, Hadley MN, Aarabi B, etal.Initial closed reduction of cervical spinal fracture-dislocation injuries. Neurosurgery 2013; 72(Suppl 2) :73-83

14 Cotler JM, Herbison GJ, Nasuti JF. Ditunno JFJ Jr, An H, Wolff BE. Closed reduction of traumatic cervical spine dislocation using traction weights up to 140 pounds. Spine 1993;18(3):386-390

15 Padwal A, Shukla D, Bhat DI, Somanna S, Devi BI. Post-traumatic cervical spondyloptosis: a rare entity with multiple management options. J Clin Neurosci 2016;28:61-66

16 Zavatsky J, Lim MR, Lee JY, Traumatic Spondyloptosis of the Cervical Spine. In: Albert TJ, Lee JY, Lim MR, eds. Cervical Spine Surgery Challenges. 2008th ed. Georg Thieme Verlag; 2008: 140-144. Doi:10.1055/b-0034-55919 
17 Shah KC, Rajshekhar V. Successful management of post-traumatic C7-T1 spondyloptosis with uninstrumented ventral surgery. Surg Neurol 2004;62(5):431-434

18 Tsujimoto T, Suda K, Harmon SM, et al. Two case reports of 'locked spondyloptosis': the most severe traumatic cervical spondyloptosis with locked spinous process and vertebral arch into the spinal canal. Spinal Cord Ser Cases 2020;6(1):10
19 Modi JV, Soman SM, Dalal S. Traumatic cervical spondyloptosis of the subaxial cervical spine: a case series with a literature review and a new classification. Asian Spine J 2016;10(6):1058-1064

20 Chadha M, Singh AP, Singh AP. Spondyloptosis of C6-C7: a rare case report. Chin J Traumatol 2010;13(6):377-379 